\title{
Risk Factors for Contracting Anthrax in Ntabeni South Ward of Kwekwe District, Zimbabwe, 2016
}

\author{
Article by Addmore Chadambuka \\ PhD Public Health, Principles and applied epidemiology, Zimbabwe \\ E-mail: achadambukal@yahoo.co.uk
}

\begin{abstract}
Background: A report of suspected human anthrax in Kwekwe District was received by Midlands Provincial Medical Director. Anthrax is a notifiable disease. We investigated factors associated with contracting anthrax in Kwekwe.

Methods: An unmatched 1:2 case control study was conducted. A case was an Ntabeni resident and satisfied the standard case definition of anthrax. Controls were residents who did not develop anthrax. Unmatched analysis was used to establish risk factors.

Results: Twenty-one cases, median age $33\left(Q_{1}=16 ; Q_{3}=49\right)$ and 43 controls, median age 33 $\left(Q_{1}=27 ; Q_{3}=44\right)$ were interviewed. Twelve cases were males. All cases had contact with dead cattle or their products. Knowledge on anthrax was low. Risk factors were skinning OR $=8.9$ (95\% CI 2.32-33.8) and cutting meat $O R=3.2$ (95\% CI 1.07-9.58). Not handling anthrax infected carcasses was protective OR $=0.06$ (95\% CI 0.01-0.3), having no cuts OR $=0.04$ (95\% CI 0.003-0.28) and having no cattle deaths in the household OR $=0.12$ (95\% CI 0.03-0.45). Epidemic preparedness and response was below the national standards. No communication system was in place. Cost of the outbreak control activities was US\$19950.

Conclusion: Outbreak resulted from contact with and consumption of anthrax infected carcasses. Skinning and cutting were risk factors for contracting anthrax. Quality of outbreak response was poor. We recommend that the district prioritize Ntabeni clinic for radio provision, hold zoonotic committee meetings and conduct an awareness campaign.
\end{abstract}

Keywords: notifiable, zoonotic committee, epidemic preparedness.

\section{Introduction}

Anthrax is a bacterial infection caused by Bacillus anthracis. The disease occurs in wild and domestic animals in Asia, Africa and parts of Europe; humans are rarely infected. The bacterium can exist in a spore form that allows the bacterium to survive in the environment for many years. ${ }^{1}$ Bacillus anthracis spores can, under favorable conditions, persist for decades before infecting a new host. ${ }^{2,3}$

Anthrax is primarily a disease of herbivores and a few warm blooded species are entirely immune to it. When conditions are not conducive for multiplication of the bacilli, they tend to form spores. The spore forms are resistant to biological extremes of heat, cold, $\mathrm{pH}$, desiccation, chemicals (and thus to disinfection), irradiation. Spore forms are the predominant phase in the environment and anthrax is contracted largely through uptake of spores. ${ }^{3}$

Humans almost invariably contract anthrax from animals. ${ }^{3}$ Contact with tissues of infected animals is the main mode of transmission. Some speculate spread of anthrax infection by insects, biting flies, that have fed on such animals, birds, scavengers, or other vectors may also be possible due to the close proximity of the infected locations. ${ }^{2,4,5}$ Contact with contaminated hair, wool, hides or their products or soils associated with infected animals or bone meal used in gardening are possible methods of transmission. 
DOI: 10.21522/TIJPH.2013.05.04.Art031

ISSN: $2520-3134$

The largest recorded outbreak of anthrax among humans occurred over two decades ago in Zimbabwe. Over 10,000 human cases and 182 human deaths were documented. Human cases were secondary to an outbreak in cattle. ${ }^{6}$

In Zimbabwe anthrax is a notifiable disease in terms of the Public Health Act Chapter 15:09. One case is an outbreak requiring notification within $24 \mathrm{hrs}$ and quick outbreak response. ${ }^{7}$

An anthrax outbreak was reported in Ntabeni South ward of Kwekwe District by the Department of Veterinary Services on the $9^{\text {th }}$ October 2016. Upon verifying with Kwekwe District, 14 human cases that satisfied the anthrax case definition had reported to Ntabeni Health Centre by $3^{\text {rd }}$ October 2016.

We set out to characterize the nature and extent of the anthrax outbreak and;

a. To describe by person, place and time the anthrax outbreak in Ntabeni South.

b. To assess the knowledge of the community on anthrax

c. To establish the risk factors contributing to contracting anthrax

d. To evaluate the quality and timeliness of outbreak response

e. To cost the outbreak control activities

\section{Materials and methods}

\section{Design}

We used a 1:2 unmatched case control design. A case was any resident of Ntabeni South who developed itching of the affected area, followed by a painful lesion which became papular, then vesiculated and eventually developed into a depressed black eschar from ${ }^{\text {st }}$ September 2016 to $10^{\text {th }}$ November 2016. Cases were identified from the clinic line list and through active case finding in the community.

A control was any resident of Ntabeni South who did not develop signs and symptoms from $1^{\text {st }}$ September 2016 to $10^{\text {th }}$ November 2016.

\section{Setting}

The study was conducted in Ntabeni South Ward of Kwekwe District

\section{Study subjects}

All the residents of Ntabeni South Ward were eligible to participate in the study.

\section{Exclusion criteria}

Children under the age of twelve were excluded from the interviews. Those who were absent from home on two consecutive visits and those that had moved out of the area were left out of the study.

\section{Sample size and calculation}

All cases during the study period were eligible for the study. Using StatCalc to calculate sample size 1:2 case control study with a power of $99 \%$ and a $95 \%$ confidence interval, a sample size of 20 cases and 40 controls was obtained. We enrolled 21 cases and 43 controls. Controls were conveniently selected from the nearest households of each case.

\section{Data collection}

We collected data using an interviewer administered questionnaire and key informant interviews with RHC staff, District Health Executive staff to assess outbreak detection and quality of outbreak response. 


\section{Data analysis}

We captured and analyzed data using Epi-info Version 3.3.2, (CDC: 2005) and generated frequencies, means, contingency tables, odds ratios and $95 \%$ confidence intervals. A p-value of 0.05 or less was statistically significant. Qualitative data was analyzed manually.

\section{Permission and ethical consideration}

We obtained permission to do the study from the Provincial Medical Director Midlands, the District Medical Officer for Kwekwe District and Health Studies Office. Verbal consent was obtained from all respondents and guardians of children that were under 18 years of age.

\section{Results}

A total 64 respondents were interviewed, 21 cases and 43 controls. Thirty two cases were reported during the outbreak.

\section{Demographic characteristics of cases and controls}

The median age for the cases was $33\left(\mathrm{Q}_{1}=16 ; \mathrm{Q}_{3}=49\right)$ and that for controls was $33\left(\mathrm{Q}_{1}=27\right.$; $\mathrm{Q}_{3}=44$ ). The mean family size for the cases was 6.1 (standard deviation $(\mathrm{SD})=2.6$ ) while that of controls was $6.5(\mathrm{SD}=2.4)$. Twelve out of the 21 cases were males whereas 23 males were among the 43 controls. Nine $(42.9 \%)$ of the cases were married compared to thirty three $(76.7 \%)$ amongst the controls. Twelve $(57.1 \%)$ of the cases were unemployed whereas all thirty seven $(86 \%)$ controls were unemployed. Eight $(38.1 \%)$ cases had attained secondary education and above whilst among the controls $23(53.5 \%)$ had attained secondary education and above (see Table 1).

\section{Description of the outbreak by person}

A total of 32 cases were line listed. Most affected were the above 15 years $(68.8 \%)$ while the least affected were the under $5(3.1 \%)$. Affected organ were the hand especially fingers 13 $(38.2 \%)$, head or face $9(26.5 \%)$ and the leg $(23.5 \%)$. Children below five years were affected on the face or head whereas those above 5 years were affected on the hands.

There were no deaths reported.

\section{Description of the outbreak by place}

Eight villages were affected and these were Gwembeni (13), Sidakwa (11), Ntabeni (3), Tsindi (2), Mhlolo, Mapanda, Mkonto and Mpama (1 case each). The most affected areas had most of the cattle deaths. Grazing area for cattle is common for the villages.

\section{Description of the outbreak by time}

The index case, 19 year old male reported to Ntabeni Clinic on 01/09/16, 4 days after onset of symptoms. Investigations revealed the case ate bovine meat on 25/08/16 suspected to have died of anthrax. More cases reported to the health facility as shown on the epi-curve (see Figure 1). The last case reported to the health facility on 27/10/16 and the cases remained 32 on 10/11/16.

The province was informed of the outbreak through the Governor's meeting on 09/10/16. Information was then relayed to the district but nothing was done as there was no transport and fuel to visit the area for investigation.

Twenty cattle died during the outbreak period. Cattle vaccination was done on 19/10/16 and no cattle deaths were reported thereafter. 
DOI: 10.21522/TIJPH.2013.05.04.Art031

ISSN: $2520-3134$

\section{Outbreak investigation and control activities}

Cases were treated with doxycycline and procaine penicillin. Health education and active case finding was conducted during interviews at households. Cattle movement from the area was restricted until three weeks after vaccination had elapsed. Cattle vaccination commenced 6 weeks after the onset of the outbreak. Efforts to control the outbreak were fragmented and uncoordinated. No Zoonotic Committees meetings were held although the committee was in place.

\section{Symptoms experienced and the treatment seeking behaviors}

All (32) cases reported having an itchy characteristic painful papule and that burst and developed a black eschar at the centre. Four (4) reported an accompanying fever, three (3) reported headache and three (3) swelling of the affected area. All cases sought treatment from the local health facilities and none from other sources. The mean delay before seeking treatment was 5.1 days ( $\mathrm{SD}=3.3$ days).

\section{Knowledge of signs and symptoms of anthrax in humans and animals}

Similar proportions of cases $14(66.7 \%)$ and controls $28(65.8 \%)$ had heard about anthrax before the outbreak. Knowledge of anthrax prevention in animals was higher among the cases 21 (100\%) than among the controls $35(81.4 \%)$. The knowledge on anthrax signs and symptoms in animals was low for both cases and controls. The knowledge on prevention of anthrax in man was similar for both the cases 4 (23.5\%) and controls 9 (23.1\%) and they all perceived prevention mean the same as treatment.

\section{Reasons for consumption of suspected anthrax infected meat}

Eight $(38.1 \%)$ of the cases reported that meat was attractive and tempting compared to twenty (46.5\%) of the controls. Similar proportions of cases 5 (23.8\%) and controls 10 (23.3\%) felt it was a waste just to throw away the meat. Identical proportions of cases $8(38.1 \%)$ and controls 17 $(39.5 \%)$ consumed meat because they did not know it would cause illness as much as $3(14.3 \%)$ cases said meat was expensive and the cattle dying were a cheap source while 6 (14.0) controls said the same.

\section{Factors associated with contracting anthrax in humans}

All (21) cases who participated in the study had handled the carcasses or their products during the different meat processing activities. Protective factors were having no cuts or wounds during skinning OR $=0.04$ (95\% CI 0.003-0.28), not handling anthrax infected carcasses or products OR $=0.06$ (95\% CI 0.01-0.3) and having no cattle deaths in the household OR $=0.12$ (95\% CI 0.030.45 ) (see Tables $4 \mathrm{a}$ and $4 \mathrm{~b}$ ).

Risk factors were cutting meat from an anthrax infected animal OR $=3.2$ (95\% CI 1.07-9.58), skinning anthrax infected carcasses OR $=8.9\left(95 \%\right.$ CI 2.32-33.8) and occupation, $\chi^{2}=10,3 \mathrm{df}(\mathrm{p}$ $=0.018)$. Marital status was a risk factor, $\chi^{2}=10.7$, $3 \mathrm{df}(\mathrm{p}=0.0048)$. Being married was associated with lesser risk OR $=0.23$ (95\% CI 0.07-0.69) see Table 4c).

\section{Epidemic preparedness and response (EPR)}

The timeliness and quality of outbreak detection, investigation and response was below the nationally set standards. The community reported to the health facility within reasonable period from onset of symptoms, that is, within four days which was only a day's delay. Table 5 shows the quality of outbreak response for the district. 


\section{Community activities}

When the community was informed by veterinary services that it was dealing with anthrax and the possibility of protecting their animals, those who could afford vaccinated their animals before veterinary services came in for vaccination.

\section{Rural health centre activities}

The staff at the centre saw the first case on $1^{\text {st }}$ September 2016. The centre experienced drug shortages and staff had to travel to Kwekwe to request for more drugs. Patients reporting to the clinic were referred elsewhere for treatment. Health education sessions were conducted to patients at the health facility. There is no radio or telephone communication and there are problems with transport. No line listing of anthrax cases was done but cases were entered into the outpatients register. A line list of the cases was drawn up on arrival to facilitate investigations.

\section{District activities}

The district reported having transport and fuel problems for them to visit the area affected by the outbreak and could not investigate the outbreak. The district managed to supply the clinic with drugs upon request and informed the District Administrator of the outbreak. Veterinary Services declared the Ntabeni South area a red zone thus restricting cattle movement out of the area. Cattle in the area were vaccinated on 19 October 2016 eight weeks after the first cattle deaths. No zoonotic committee or civil protection meetings were held to organise and coordinate an outbreak response (see Table 5).

\section{Cost of outbreak control activities}

Several costs were incurred during the control of the outbreak. A cost analysis was conducted to inform future activities. The costs are shown in Table 6.

\section{Discussion}

The outbreak had several peaks showing an ongoing intermittent exposure as people ate or came in contact with cattle dying of anthrax.

The investigation revealed a delay in notification, investigating and responding to the outbreak. The surveillance system was not sensitive enough to transmit outbreak information on time.

Skinning and cutting meat were statistically significant risks in this study. Cuts were likely to have occurred during these processes which exposed the individuals to infection. This is consistent with the findings of Mwenye et al in Murewa and Kumar A et al in India in their investigations on anthrax risk factors. ${ }^{8,14}$

Having cuts or open wound during processing in areas likely to come into contact with infected material increased the risk of contracting anthrax. These areas are unobstructed routes of entry for large numbers of bacteria compared with an intact skin. This was consistent with what Woods CW et al found out in an anthrax outbreak in Kazakhstan'.

Having no cattle deaths in the household was found protective from contracting anthrax. This was because the chances of coming in contact with infected meat or products were reduced unlike the household where cattle deaths occurred where members would be actively involved in skinning and cutting for sale and consumption.

Marital status was found to be associated with anthrax. Being married meant the elder people who are more likely to married tend to delegate duties to the younger ones. This reduced the chances of contact with the infected meat and thus the reduced risk.

The position of the majority of anthrax lesions was on the fingers and the face with a few around the chest and neck. Reasons are that the hands especially the fingers are mainly in contact with the infected products while the face is exposed during consumption probably of 
DOI: 10.21522/TIJPH.2013.05.04.Art031

ISSN: $2520-3134$

undercooked meat. The neck and chest are exposed while carrying the meat cuts for storage from the place of slaughter. ${ }^{12,13}$

No case fatality was recorded in this outbreak. This is consistent with findings of Lakshmi $N$ et $a l$ in India ${ }^{10}$. Other literature confirm very low case fatality rates are recorded with treatment of cases. ${ }^{11,12}$

In this study, the knowledge levels on anthrax were low. This is opposite what Opare $C$ et al found out in Ghana where knowledge levels were as high as $96 \%{ }^{15}$

\section{Limitation}

The study was conducted towards the end of the outbreak when vaccination and health education had already been in progress. This could have affected the knowledge levels of the people. Recall bias cannot be ruled out as six weeks had elapsed when some of the respondents were asked of their experiences

\section{Conclusion}

The outbreak resulted from contact with and consumption of anthrax infected carcasses, meat and meat products. Quality of outbreak response was poor. Activities of sector ministries were fragmented and uncoordinated and should be better coordinated. Community knowledge on anthrax was poor. Handling carcasses or meat, being married and being unemployed were risk factors for contracting anthrax and were statistically significant. Belonging to a household that had no cattle deaths and having no cuts or wounds were protective for anthrax.

\section{Recommendations}

District should hold zoonotic committee meetings to coordinate outbreak response activities. The zoonotic committee should meet on a regular basis e.g. quarterly and more often during outbreaks of zoonoses.

District in liaison with health promotion should organize awareness campaign on anthrax to improve community's knowledge levels

The district should prioritize Ntabeni clinic for the provision of radio communication to improve dissemination of surveillance information

The district should prioritize emergencies and ensure that resources are made available to attend to them.

The district health executive should consider motorizing the EHT from the neighbouring clinic for her to be more effective considering the large catchment she has to cover.

The zoonotic committee should meet on a regular basis and more often during outbreaks of zoonoses.

\section{References}

[1].Anthrax General Information: Issued by PHLS-CDSC. Version: M1, issue date: 10 December 2002

[2].Hugh-Jones M. 1996-97 Global Anthrax Report. Journal of Applied Microbiology 1999; 87:189-191,

[3].Guidelines for the Surveillance and Control of Anthrax in Humans and Animals, $3^{\text {rd }}$ Edition, PCB

Turnbull. World Health Organization, 1998.

Dragon DC, Rennie RP. The ecology of anthrax spores: tough but not invincible. Canadian Veterinary

Journal 1995; 36:295-301,

Gates CC, Elkin BT, Dragon DC. Investigation, control and epizootiology of anthrax in a geographically

isolated, free-roaming bison population in Northern Canada.

[4].Canadian Journal of Veterinary Research 1995; 59:256-264).

[5].A major epidemic of anthrax in Zimbabwe, Part 1. Davies JCA. Central African Journal of Medicine

1982; 28:291-298.

[6].Zimbabwe Public Health Act, CAP 15:09, Revised Edition 1996: Government Printers, Harare 
[7].Factors associated with human anthrax outbreak in the Chikupo and Ngandu villages of Murewa District, Mashonaland East; Mwenye KS, Siziya S, Peterson D: Central African Medical Journal Nov 1996 42(11): $312-5$

[8].Risk factors for human anthrax among contacts of anthrax-infected livestock in Kazakhstan. Woods CW, Ospanov K, Myrzabekov A, Favorov M, Plikaytis B, Ashford DA: American Journal Tropical Medicine Hygiene. 2004 Jul; 71(1):48-52.

[9].An epidemic of human anthrax--a study. Lakshmi N, Kumar AG: Indian Journal Pathology and Microbiology. 1992 Jan; 35(1):1-4.

[10]. Frequently Asked Questions about Anthrax: Centres for Disease Control, updated 30/10/01 www.cdc.gov: Accessed 21/09/16

[11]. Control of Communicable Diseases Manual: Chin J. American Public Health Association; $17^{\text {th }}$ Edition (20)

Factors associated with contracting anthrax in Chirozva area, Buhera District; Mabaera B, Tshimanga M., Mudyiradima R., Siziya S. Emerging and Re-emerging Infections Part II: Abstract 2.9.

[12]. Human anthrax in India: urgent need for effective prevention. Kumar A, Kanungo R, Bhattacharya S, Badrinath S, Dutta TK, Swaminathan RP: Journal of Communicable Diseases. 2000 Dec; 32(4):240-6 Human behavioural factors implicated in outbreaks of human anthrax in the Tamale municipality of northern Ghana. Opare C, Nsiire A, Awumbilla B, Akanmori BD. Acta Tropica. 2000 Jul 21; 76(1):49-52.

Table 1. Demographic characteristics of cases and controls

\begin{tabular}{lll}
\hline Variable & Cases $(\mathbf{n}=\mathbf{2 1})$ & Controls $(\mathbf{n}=\mathbf{4 3})$ \\
\hline Median age (yrs) & $33\left(\mathrm{Q}_{1}=16 ; \mathrm{Q}_{3}=49\right)$ & $33\left(\mathrm{Q}_{1}=27 ; \mathrm{Q}_{3}=44\right)$ \\
Mean Family Size & $6.1(\mathrm{SD} \pm 2.6)$ & $6.5(\mathrm{SD} \pm 2.4)$ \\
Sex & 12 & 23 \\
M & 9 & 20 \\
F & & \\
Educational Level & $8(38 \%)$ & $23(53 \%)$ \\
Secondary + & $13(62 \%)$ & $20(47 \%)$ \\
Primary & 11 & 6 \\
Marital Status & 9 & 33 \\
Single & 1 & 4 \\
Married & & \\
Widowed & &
\end{tabular}

Table 2. Knowledge on anthrax among cases and controls

\begin{tabular}{lllll}
\hline Knowledge on Anthrax & Cases & \multicolumn{3}{c}{ Controls } \\
\cline { 2 - 5 } & $\mathbf{N}$ & $\mathbf{\%}$ & $\mathbf{N}$ & $\mathbf{\%}$ \\
\hline Had heard of anthrax before outbreak & $14 / 21$ & 66.7 & $28 / 43$ & 65.1 \\
Knew about cattle deaths in the area & $21 / 21$ & 100 & $43 / 43$ & 100 \\
Knowledge of anthrax prevention in animals & & & & \\
Dipping & $0 / 21$ & 0 & $1 / 43$ & 2.3 \\
Vaccination & $21 / 21$ & 100 & $35 / 43$ & 81.4 \\
Knowledge of signs and symptoms in animals & & & & \\
Cessation of feeding & $4 / 21$ & 19.0 & $7 / 43$ & 16.3 \\
Death within 24hrs & $7 / 21$ & 33.3 & $13 / 43$ & 30.2 \\
Massive edema & $4 / 21$ & 19.0 & $6 / 43$ & 14.0 \\
Bleeding orifices & $3 / 21$ & 14.3 & $2 / 43$ & 4.7 \\
Did not know & $7 / 21$ & 33.3 & $16 / 43$ & 37.2 \\
Knowledge of anthrax prevention in man & & & &
\end{tabular}


DOI: $10.21522 / \mathrm{TIJPH} .2013 .05 .04 . A r t 031$

ISSN: $2520-3134$

Avoiding contact with infected meat animal

$$
4 / 17 \quad 23.5 \quad 9 / 39
$$

products

Treatment

$\begin{array}{llll}11 / 17 & 64.7 & 30 / 39 & 76.9\end{array}$

Knowledge of socioeconomic implications of anthrax

Loss of school/work time

$5 / 21$

23.8

$5 / 43$

11.6

Loss of wealth

$2 / 21$

9.5

$7 / 43$

16.3

Loss of draught power

$2 / 21$

9.5

7.0

Suffering and/loss of life

$0 / 21$

$3 / 43$

60.4

Table 3. Reported reasons for consumption of anthrax infected meat

\begin{tabular}{lllll}
\hline Reasons why people consume meat from & Cases & \multicolumn{3}{l}{ Control } \\
\cline { 2 - 5 } animals that die of suspected anthrax & $\mathbf{N}$ & $\mathbf{\%}$ & $\mathbf{N}$ & $\mathbf{\%}$ \\
\hline Meat is attractive and are tempted to eat & $8 / 21$ & 38.1 & $20 / 43$ & 46.5 \\
People have no choice but just to eat & $1 / 21$ & 4.8 & $3 / 43$ & 7.0 \\
People feel it's a waste just to throw away & $5 / 21$ & 23.8 & $10 / 43$ & 23.3 \\
People do not know it causes illness & $8 / 21$ & 38.1 & $17 / 43$ & 39.5 \\
Meat is expensive and rarely eaten, cheap source & $3 / 21$ & 14.3 & $6 / 43$ & 14.0 \\
I don't know & $8 / 21$ & 38.1 & $3 / 43$ & 7.0 \\
\hline
\end{tabular}

Table 4a. Risk factors for contracting anthrax

\begin{tabular}{|c|c|c|c|c|c|c|}
\hline \multirow{2}{*}{$\begin{array}{l}\text { Risk factor/exposure } \\
\text { variable }\end{array}$} & \multicolumn{2}{|c|}{ Cases } & \multicolumn{2}{|c|}{ Controls } & \multirow[t]{2}{*}{ OR } & \multirow[t]{2}{*}{$95 \% \mathrm{CI}$} \\
\hline & Yes & No & Yes & No & & \\
\hline Handling carcass/products & 19 & 2 & 16 & 27 & 0.06 & $0.01-0.3^{*}$ \\
\hline $\begin{array}{l}\text { Cutting meat from anthrax } \\
\text { infected animal }\end{array}$ & 11 & 10 & 11 & 32 & 3.2 & $1.07-9.58^{*}$ \\
\hline $\begin{array}{l}\text { Cooking meat from anthrax } \\
\text { infected animal }\end{array}$ & 8 & 13 & 13 & 30 & 1.4 & $0.47-4.25$ \\
\hline $\begin{array}{l}\text { Skinning anthrax infected } \\
\text { animal }\end{array}$ & 10 & 11 & 4 & 39 & 8.9 & $2.32-33.8^{*}$ \\
\hline Drying the meat & 1 & 20 & 2 & 41 & 1.02 & $0.09-12$ \\
\hline $\begin{array}{l}\text { Belonging to a restrictive } \\
\text { religion }\end{array}$ & 4 & 17 & 9 & 34 & 0.89 & $0.24-2.46$ \\
\hline $\begin{array}{l}\text { Having no cattle deaths in } \\
\text { the HH }\end{array}$ & 10 & 11 & 4 & 37 & 0.12 & $0.03-0.45^{*}$ \\
\hline Having no cuts/wounds & 2 & 17 & 13 & 4 & 0.04 & $0.003-0.28 *$ \\
\hline
\end{tabular}

* Statistically significant

Table 4b. Risk factors for contracting anthrax

\begin{tabular}{lllll}
\hline Risk factor & Cases & Controls & OR & 95\% CI \\
$\begin{array}{l}\text { Marriage State } \\
\text { Married }\end{array}$ & 9 & 33 & 0.23 & $0.07-0.69^{*}$ \\
$\begin{array}{l}\text { Single } \\
\text { Employment }\end{array}$ & 12 & 10 & & \\
$\begin{array}{l}\text { Status Unemployed } \\
\text { Age Group }\end{array}$ & 5 & 1 & 0.06 & $0.001-0.69^{*}$ \\
$\leq 18$ years & 12 & 37 & & \\
& 6 & 2 & 8.2 & $1.2-88.2^{*}$
\end{tabular}


Table 4c. Risk factors for contracting anthrax (continued)

\begin{tabular}{lll}
\hline Risk factor & $\chi^{2}$ & p-value \\
\hline Having cuts /wounds during & 18.3 & $0.0001^{*}$ \\
handling & & \\
Marital status & 10.7 & $0.0048^{*}$ \\
Occupation & 10 & $0.018^{*}$ \\
\hline
\end{tabular}

Table 5. Timeliness and quality of outbreak detection, investigation and response

\begin{tabular}{|c|c|c|c|}
\hline Activity & Target & Achievement & Comment \\
\hline $\begin{array}{l}\text { 1. Interval between occurrence of } \\
\text { first case at the community level to } \\
\text { arrival of first outbreak case at the } \\
\text { health facility }\end{array}$ & 3 days & 4 days & 1 day delay \\
\hline $\begin{array}{l}\text { 2. Interval between initial outbreak } \\
\text { case seen at the health facility and } \\
\text { reporting to the district health team }\end{array}$ & $24 \mathrm{hrs}$ & 40 days & 38 days delay \\
\hline $\begin{array}{l}\text { 3. Cumulative interval between onset } \\
\text { of first case in the community or } \\
\text { health facility to notification to the } \\
\text { district }\end{array}$ & $<7$ days & 40 days & 33 days delay \\
\hline 4. Case forms/ line list completed? & Yes & Yes & Done \\
\hline $\begin{array}{l}\text { 5. Interval between notification of } \\
\text { district and district field investigation } \\
\text { conducted }\end{array}$ & $48 \mathrm{hrs}$ & 3 weeks & 19 days delay \\
\hline $\begin{array}{l}\text { 6. Interval between notification of } \\
\text { outbreak to district and concrete } \\
\text { response by the district }\end{array}$ & $48 \mathrm{hrs}$ & 3 weeks & 19 days delay \\
\hline $\begin{array}{l}\text { 7. Interval between end of outbreak } \\
\text { and finalization of outbreak report } \\
\text { with case forms/line list sent to } \\
\text { higher level }\end{array}$ & 2 weeks & 2 weeks & Achieved \\
\hline $\begin{array}{l}\text { 8. Outbreak management committee } \\
\text { met? }\end{array}$ & Yes & No & Not achieved \\
\hline $\begin{array}{l}\text { 9. Feedback to health facility and } \\
\text { community? }\end{array}$ & Yes & To be done & \\
\hline
\end{tabular}

Table 6. An analysis of costs in an anthrax control in ntabeni south ward of kwekwe district, zimbabwe 2016

\begin{tabular}{|c|c|c|}
\hline Activity & Unit cost & Total cost (US\$) \\
\hline Human Resources (Allowances) & & 7500 \\
\hline Fuel and transportation & & 1000 \\
\hline $\begin{array}{l}\text { Treatment of cases (drugs, nurses time } \\
\text { etc.) }\end{array}$ & & 3250 \\
\hline Materials and supplies (pen, paper, etc.) & & 100 \\
\hline
\end{tabular}


DOI: 10.21522/TIJPH.2013.05.04.Art031

ISSN: $2520-3134$

Case finding (home visits, surveillance) 2150

IEC material

Cost of cattle vaccination in area

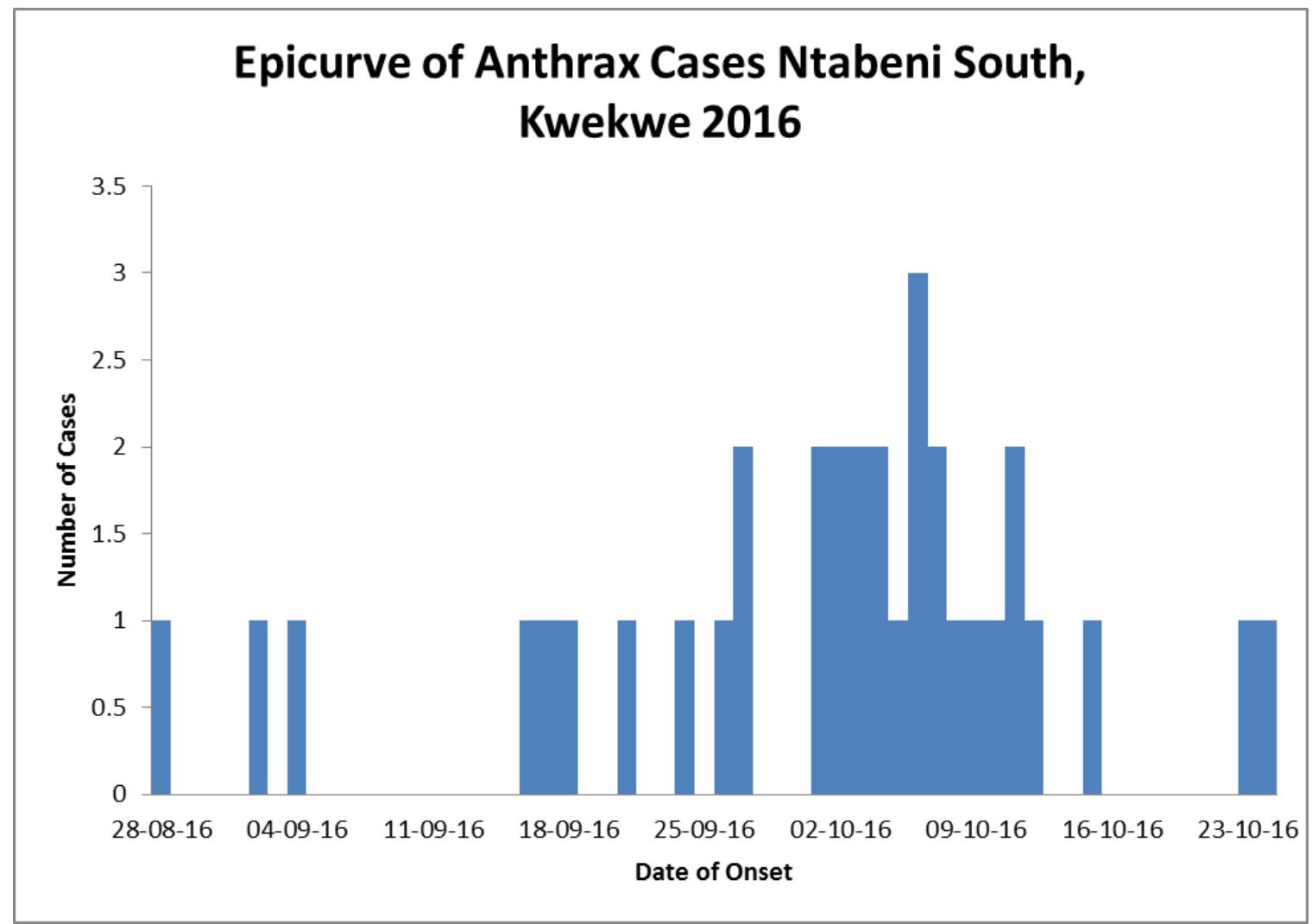

Figure 1. Epi-curve of the anthrax outbreak in Ntabeni South Ward, Kwekwe District Zimbabwe 2016 